\title{
ESTIMATION OF IMPLICIT CARBON IN ENERGY TRADE BETWEEN CHINA AND OTHER COUNTRIES ALONG THE BELT AND THE ROAD BASED ON MULTI-REGIONAL INPUT-OUTPUT MODEL
}

\author{
JIA, X. M. ${ }^{1,2}-$ WANG, X. L. ${ }^{3 *}$ \\ ${ }^{1}$ School of Management, Xi'an University of Architecture and Technology \\ Xi'an, 710055, China \\ ${ }^{2}$ Business College, Xi'an International University Xi'an, 710077, China \\ ${ }^{3}$ School of Management, Energy Economics and Management Research Center \\ $X i$ 'an University of Science and Technology, Xi'an, 710054, China \\ *Corresponding author \\ e-mail:wxllian@sina.com \\ (Received $18^{\text {th }}$ Mar 2019; accepted $17^{\text {th }}$ May 2019)
}

\begin{abstract}
Considering the transfer of carbon emissions between the countries along the Belt and the Road and the importance of responsibility sharing for carbon emissions to international trade, this paper measures the implicit carbon in the trade between China and other countries along the Belt and the Road by the multi-regional input-output (MRIO) method. The measured results show that the trade between the two sides accounts for 3\% 21\% of the total carbon emissions in China; China's carbon responsibilities in its trade with the top trade partners along the Belt and the Road differs greatly with responsibility sharing principles; implicit carbon emissions mainly come from industries with relatively high emission intensities; China is advised to adopt the common responsibility mechanism. The research findings shed new light on the estimation of implicit carbon in international trade.
\end{abstract}

Keywords: carbon emission, international trade, producer responsibility, consumer responsibility, reduction of carbon emission

\section{Introduction}

Economic development and scientific progress have promoted the international division of labor, affecting the trade circulation of many countries. Typically, commodity production and final consumption occur in different geographic regions. Therefore, a country can reduce domestic production by importing commodities, thereby reducing domestic carbon emissions. This international trade model, while reducing the carbon emissions in consumer countries, causes pollution to rise in producing and exporting countries. The consumer countries should bear the corresponding carbon emission responsibilities. The current responsibility sharing system for carbon emission reduction only highlights the producer responsibility for production-side emissions of each country, that is, a country should be responsible for the greenhouse gases (GHGs) released in the production of commodities for export or domestic consumption. This system fails to consider the responsibility of foreign and domestic consumers for the carbon emissions. Compared with big exporters, large importers need to assume much responsibility for product consumption.

Since joining the World Trade Organization (WTO), China has actively participated in the global division of labor, witnessing a significant growth in the volume of foreign 
trade.The country has gradually evolved into a major manufacturer in global trade, and won the nickname of the world's factory. From 2001 to 2016, the total import and export volume occupied from 0.51 trillion USD to 3.96 trillion USD (Boamah et al., 2017). The rapid growth in trade is accompanied by the emission of a huge amount of GHG emissions. The 2015 United Nations Climate Change Conference (COP 21) reported that China contributed $20 \%$ to the global GHG emissions, most of which originate from the production of export commodities (Cozier, 2016). This means China suffers from the carbon emissions caused by countries importing its commodities, which should be considered in the design of the responsibility sharing system for carbon emission reduction.

In 2013, China, the largest developing country in the world, launched the Belt and Road Initiative, with the aim to deepen the trade exchange with other countries. At present, the trade with the countries along the Belt and the Road occupies an important position in China's international trade. Under the circumstances, it is imperative to China's responsibilities for carbon emission reduction by quantifying the carbon emissions in commodity production and trade and determining the quantity and flow of implicit carbon in trade (Liu et al., 2017; Zhang, 2017; Tu and Ma, 2018).

The implicit carbon in trade is usually estimated by top-down accounting and bottom-up accounting. The former approach is specified in the IPCC Task Force on National Greenhouse Gas. This relatively authoritative method requires the classification and decomposition of the carbon emission sources. The latter approach, grounded on enterprise commodities and projects, has certain limitations, as it cannot cover all enterprises or commodities.

The commonly used accounting strategies or carbon emissions can be listed as the emission coefficient method, lifecycle method, and input-output (I-O) method, in light of the research perspective. The emission coefficient method adopts an emission coefficient factor, which is defined as the proportion of air pollutant to all pollutants generated by production activities. For example, Li et al. (2018) employed this method to measure the carbon emissions in the operation phase of a building.

The lifecycle method mainly assess the environmental factors and potential impacts associated with a product or service. Specifically, the related inputs and outputs of a system were recorded, and subjected to correlation analysis. Then, the analysis results are explained through lifecycle assessment, revealing the potential environmental impacts. For instance, Shi (2017) reviewed the development in animal husbandry research fromcarbon emissions to carbon footprint. Bello et al. (2018) calculated the carbon emissions in the lifecycle of buildings, and established a carbon footprint evaluation model for the whole lifecycle of residential buildings. With the aid of lifecycle method, Li (2016) determined the trend and flow of the implicit carbon in China's import and export in the past decade.

The I-O method studies how the commodities of a country affect the environment through international circulation. This strategy can be subdivided into single-regional IO (SRIO) method, bi-regional I-O (BRIO) method, and multi-regional I-O (MRIO) method. The SRIO treats regions other than the producing country as one entity rather than distinguish between product sources, and assumes that the technology is on the same level at home and abroad. Despite its simplicity, this method cannot measure the consumption of intermediate commodities, or give an accurate depiction of the product flow in global trade. Under the assumption of technical heterogeneity, the BRIO selects different carbon emission factors for different trades. Neither can this method accurately 
reflect the circulation of intermediate commodities. By contrast, the MRIO fully considers the production and circulation of different industries in different countries, yielding accurate measurement results (Tan et al., 2014). As a result, the MRIO is more widely applied than the other two methods to measure the implicit carbon in international trade.

Diezenbacher et al. (2012) suggested splitting the trade of an enterprise into processing trade and general trade, aiming to prevent the overestimation of implicit carbon in trade by the traditional I-O method (Su and Ang, 2011; Xia et al., 2015). Considering the difference in corporate ownership, Liu et al. (2016) analyzed the implicit carbon of China's trade by extended I-O, and suggested the overlook of corporate heterogeneity will exaggerate the implicit carbon emissions by $20 \%$. Wei and Peng (2017) used the MRIO model to measure the energy sources related to China-US trade between 1995 and 2009, revealing that the exports to the US have become a major emission source to China. Li (2017) estimated the implicit carbon emissions incurred in Chinese and Japanese exports to countries along the Belt and the Road based on the GTAP9 database, discovered the implicit carbon difference in trade between these countries, and attributed the difference to the trade volume, implicit carbon intensity and trade structure of China and Japan. Lan (2015) relied on MRIO to estimate the implicit carbon of China-EU trade, and verified if the bilateral trade causes the flow of EU carbon emissions to China. Sun (2016) measured the implicit carbon in China's export based on the I-O data in 2002, 2005, 2007, 2010 and 2012, concluding that the amount of implicit carbon increased 2.42 times from 471 million tons in 2002 to 1.056 billion tons in 2015. From the angle of intrinsic emissions, Fang and $\mathrm{Xu}$ (2013) found that most of the $\mathrm{CO}_{2}$ generation in China is to satisfy the needs of other countries. Under consumer responsibility, Gao (2016) calculated the implicit carbon of various countries, decomposed the implicit carbon structure, and looked for the causes to difference in carbon emissions through multiple methods. Pan and Wu (2018) measured the implicit carbon of China-Japan trade using the World Input-Output Database (WIOD), pointing out China's deficit of implicit carbon in the trade and the concentration of export implicit carbon in the heavy industry. Yu and Wang (2017) evaluatedthe implicit carbon of trade between China and 36 countries and regions, decomposed the implicit carbon by structural decomposition analysis, and drew the following conclusions: China is faced with a net inflow of implicit carbon and needs to upgrade emission reduction technologies and reduce thecarbon emission intensity.

On the responsibility sharing of carbon emissions, more and more scholars have questioned about the fairness of the current producer responsibility emission reduction model. For instance, Munksgaard (2001) proved that it is difficult for Denmark to achieve its carbon emission reduction target, if the implicit carbon in its export is counted as domestic carbon emissions, as required by the principle of producer responsibility. Using the Trade in Value Added (TiVA) database, Xiao (2016) measured the residual GHG emissions of the producing countries, which arises from the final consumption of commodities in consumer countries, and suggested the consumer countries be the main undertaker of carbon emission responsibilities. Dong et al. (2018) carried out adata envelopment analysis (DEA) on responsibility sharing for implicit carbon in trade among different provinces in China, and divided these provinces into four regions. Comparing producer responsibility and consumer responsibility, $\mathrm{Yu}$ and $\mathrm{Xu}$ (2017) noted that China will assume fewer responsibilities for emission reduction under consumer responsibility than under producer responsibility. To relieve global 
environmental pressure, Zhong et al. (2018) came up with an effective strategy for global energy conservation and emission reduction: upgrading production technologies and increasing the proportion of clean energy in total energy consumption. Wang et al. (2017) estimated the carbon emissions of 30 provincial administrative regions in Chinese mainland, discovered obvious net carbon exports from the eastern coast, the southern coast and the Beijing-Tianjin region, and found a clear net carbon transfer from the northwest. Pan et al. (2008) argued that developed countries can manipulate the producer responsibility system and transfer their carbon emissions to developing countries through trade, causing carbon leakage and pushing up global carbon emissions.

Hence, some scholars have proposed to replace the producer responsibility system with consumer responsibility, i.e. including the carbon emissions from the final consumption of self-produced and imported commodities into the total carbon emissions of a country. The consumer responsibility system can mitigate the carbon leakage. However, some problems may occur to the carbon emission efficiency of exporting countries or industries, as the carbon emission responsibility is passed to the final consumers.

In light of the above, this paper selects the major trade partners of China along the Belt and the Road, and employs the MRIO method to calculate the implicit carbon in their trade with China.

\section{Materials and methods}

The MRIO model consisting of $n$ different countries can be expressed as Eq.1:

$$
\left(\begin{array}{c}
x_{1} \\
x_{2} \\
\mathrm{M} \\
x_{n}
\end{array}\right)=\left(\begin{array}{cccc}
A_{11} & A_{12} & \mathrm{~L} & A_{1 n} \\
A_{21} & A_{22} & \mathrm{~L} & A_{2 n} \\
\mathrm{M} & \mathrm{M} & \mathrm{M} & \mathrm{M} \\
A_{n 1} & A_{n 2} & \mathrm{~L} & A_{n n}
\end{array}\right) \bullet\left(\begin{array}{c}
x_{1} \\
x_{2} \\
\mathrm{M} \\
x_{n}
\end{array}\right)+\left(\begin{array}{c}
y_{11}+\sum_{i \neq 1} y_{1 i} \\
y_{22}+\sum_{i \neq 2} y_{2 i} \\
\mathrm{M} \\
y_{n n}+\sum_{i \neq n} y_{n i}
\end{array}\right)
$$

where $A_{n n}$ is the direct consumption coefficient of domestic commodities in each country; $A_{i j}$ is the mutual demand between two countries, as reflected by the bilateral trade activities; $x_{i}$ is the output vector of country $i ; y_{i i}$ means country isatisfies the domestic demand for commodities; $y_{i r}$ means country $i$ satisfies the demand of country $r$ for commodities, i.e. the final demand. Eq.l can be simplified as $X=A X+Y$, and rewritten as $X=(I-A)^{-1} Y$, with $X$ being the world output vector and $Y$ being the final supply vector of each country, including household consumption, government consumption, capital formation and inventory changes.

According to the Kyoto carbon accounting model, the production-side emissions refer to the carbon emissions fromcommodity production in a country, which has nothing to do with the consumption of the commodities. In this case, the total carbon emissions of a country is equivalent to the domestic production emissions. On the contrary, the consumer responsibility system considers both domestic and foreign carbon emissions caused by the final demand as the responsibility of the country. Thus, the consumption-side carbon emissions equalthe domestic emissions plus the foreign emissions. 
Let $F_{w}=\left(f_{1}, f_{2} \cdots f_{m}\right)$ be the world's emission intensity vector, with $f_{1} \sim f_{m}$ being the carbon emissions from commodity production in different industries of the country, $Y=\left(y_{1}, y_{2}, \cdots, y_{i}, \cdots, y_{n}\right)$ be the final commodities that meet the foreign demand, with $y_{2}, y_{i}$ and $y_{n}$ being the final demand vectors of the country, and $(I-A)^{-1}=L$ be the Leontief I-O matrix. Based on the MIRO model, the production-side carbon emissions of country $i$ can be described as Eq.2:

$$
E_{i}^{p}=f_{i} x_{i}=f_{i} L Y
$$

where $E_{i}$ is the total production-side carbon emissions of country $i$. The production-side carbon emissions can be further split into those meeting domestic demand and those meeting foreign demand, while the commodities that satisfy foreign demand can be subdivided into intermediate commodities and final commodities. Taking China as country $i(i=1)$, the production-side carbon emissions of China can be expressed as Eq.3:

$$
E_{1}^{p}=f_{1} x_{11}+f_{1} \sum_{i \neq 1} x_{1 i}=f_{1} x_{11}+f_{1} L_{11} \sum_{i \neq 1} \sum_{r \neq 1} A_{1 r} x_{r i}+f_{1} L_{11} \sum_{i \neq 1} y_{1 i}
$$

where $L_{11}=\left(I-A_{11}\right)^{-1}$ is the Leontief I-O matrix of China. Similarly, China's consumption-side carbon emissions are generated across the world to satisfy the country's final demand. In this paper, China's consumption-side emissions refer specifically to the country's carbon emissions from the consumption of the final commodities in countries along the Belt and the Road. Hence, the consumption-side emissions of China can be expressed as Eq.4:

$$
E_{1}^{c}=f_{i} L y_{1}
$$

China's consumption-side emissions can be broken down into domestic emissions and foreign emissions. The former equals the country's production-side emissions that meets domestic demand, while the latter consists of the carbon emissions from foreign countries, which are generated through the intermediate and final commodities imported by China to satisfy its domestic demand. Thus, Eq.4 can be rewritten as Eq.5:

$$
E_{1}^{c}=f_{1} x_{11}+\sum_{i \neq 1} f_{i} x_{i 1}=f_{1} x_{11}+\sum_{r \neq 1} f_{r} L_{r r}\left(A_{r 1} x_{11}+y_{r 1}\right)+\sum_{r \neq 1}\left(f_{r} L_{r r} \sum_{i \neq 1, i \neq r} A_{r i} x_{i 1}\right)
$$

where $\sum_{r \neq 1} f_{r} L_{r r}\left(A_{r 1} x_{11}+y_{r 1}\right)$ and $\sum_{r \neq 1}\left(f_{r} L_{r r} \sum_{i \neq 1, i \neq r} A_{r i} x_{i 1}\right)$ are the carbon emissions from direct imports and indirect imports, respectively.

There are three responsibility sharing systems for carbon emissions, namely, producer responsibility, consumer responsibility and common responsibility. The producer responsibility means the producer is responsible for the carbon emissions from the commodities produced within its territory, regardless if the commodities are consumed domestically or overseas. Despite its simplicity, this accounting approach neglects the shift of carbon emissions under trade, and hinders the emission reduction in developing countries with high carbon intensity. The consumer responsibility requires the consumer to assume part of the responsibility for carbon emissions. Compared to the 
producer responsibility system, this approach can mitigate carbon leakage, andpromote carbon emissions reduction and economic growth in developing countries like China. The common responsibility means both the producer and consumer should be responsible for carbon emissions. Under this system, a country's responsibilities are the sum of the producer's responsibility and the consumer's responsibility. Inspired by Pan et al. (2008), a country's total carbon emissions can be divided into five parts, as shown in Eq.6:

$$
E=f_{1} x_{11}+f_{1} L_{11} \sum_{i \neq 1} \sum_{r \neq 1} A_{1 r} x_{r i}+f_{1} L_{11} \sum_{i \neq 1} y_{1 i}+\sum_{\mathrm{r} \neq 1} f_{r} L_{r r}\left(A_{r 1} x_{11}+y_{r 1}\right)+\sum_{\mathrm{r} \neq 1}\left(f_{r} L_{r r} \sum_{i \neq 1, i \neq r} A_{r i} x_{i 1}\right) \text { (Eq.6) }
$$

Under the common responsibility system, China's responsibilities for carbon emissions can be expressed as Eq.7:

$$
(1-m)\left(f_{1} L_{11} \sum_{i \neq 1} \sum_{r \neq 1} A_{1 r} x_{r i}+f_{1} L_{11} \sum_{i \neq 1} y_{1 i}\right)+m\left[\sum_{\mathrm{r} \neq 1} f_{r} L_{r r}\left(A_{r 1} x_{11}+y_{r 1}\right)+\sum_{\mathrm{r} \neq 1}\left(f_{r} L_{r r} \sum_{i \neq 1, i \neq r} A_{r i} x_{i 1}\right)\right] \text { (Eq.7) }
$$

where $m$ is the sharing factor; the first term in the second pair of brackets is the carbon emissions from intermediate commodities produced to meet domestic demand; the second term of the second pair of brackets is the carbon emissions from commodities produced to meet foreign demand; the part in the pair of square brackets is the carbon emissions from imported commodities that meet the domestic demand. The rest of the responsibilities should be borne by other countries along the Belt and the Road. This paper sets the sharing factor to $60 \%$, such that the most able countries take greater shares and that consumers assume part of the responsibilities.

The research data were extracted from the WIOD database, which includes the I-O data of 40 countries and regions across the world. The data of each country is divided into 56 industries. Here, 36 industries are adopted in the global MRIO table according to the Industrial Classification for National Economic Activities (GB/T 4754-2017) (Table 1).

Table 1. Industry reclassification summary of multi-area input-output tables in the world

\begin{tabular}{c|c|c|c}
\hline Code & Name of Product department & Code & Name of Product department \\
\hline $\mathrm{Ag}$ and & Agriculture, forestry, animal husbandry & $\mathrm{Au}$ & Automobile, motorcycle manufacturing repair \\
$\mathrm{Mi}$ & Mining industry & $\mathrm{Re}$ & Other retail and home repairs \\
$\mathrm{Fo}$ & Food, beverage and tobacco product & $\mathrm{Ac}$ & Accommodation and food service activities \\
$\mathrm{Te}$ & Textiles, Apparel and Leather Products & $\mathrm{La}$ & Land transport and pipeline transportation \\
$\mathrm{Wo}$ & Wood products and cork products, except & $\mathrm{Wt}$ & Water transport activities \\
$\mathrm{Pa}$ & Paper and Printing & $\mathrm{Ai}$ & Air transport activities \\
$\mathrm{Pc}$ & Production of coke and refined petroleum & $\mathrm{Ta}$ & Other transportation activities \\
$\mathrm{Ch}$ & Chemical manufacturing & $\mathrm{Po}$ & Post and Telecommunications \\
$\mathrm{Ru}$ & Rubber and plastic products manufacturing & $\mathrm{Fi}$ & Financial industry \\
$\mathrm{Nm}$ & Othernon-metallic mineral products & $\mathrm{Re}$ & Real estate activity \\
$\mathrm{Me}$ & Metal manufacturing & $\mathrm{Le}$ & Leasing and business services \\
$\mathrm{Ma}$ & Machinery and equipment manufacturing & $\mathrm{Sc}$ & Scientific research and technology service \\
$\mathrm{Ee}$ & Electrical equipment manufacturing & $\mathrm{Pu}$ & Public administration and defense \\
$\mathrm{Tr}$ & Transportation equipment manufacturing & $\mathrm{Ed}$ & Education \\
$\mathrm{Fu}$ & Furniture and other wood products & $\mathrm{Hu}$ & Human health and social work activities \\
$\mathrm{Wa}$ & Waste treatment industry & $\mathrm{Se}$ & Other service activities \\
$\mathrm{Eh}$ & Electricity, heat, gas and water production & $\mathrm{Un}$ & Undifferentiated goods and services \\
$\mathrm{Co}$ & Construction industry & $\mathrm{Ex}$ & Extra-territorial organization activities \\
\hline
\end{tabular}


The data on the countries appear both in the WIOD database and on the Belt and Road Portal (www.yidaiyilu.gov.cn/) were downloaded, including but not limited to South Korea, India, Indonesia, Russia, Turkey, Czech Republic, Slovakia, Romania, Greece, Slovenia, Estonia, Bulgaria, Lithuania, Latvia, Croatia, Malta and Cyprus. Among them, the top five trade partners of China, namely, South Korea, India, Indonesia, Russia and Turkey, were selected for further analysis. In terms of trade volume, these countries account for $91.98 \%$ of China's trade along the Belt and the Road. Thus, it is suitable to compute the production-side and consumption-side implicit carbon with the data of these countries.

\section{Results and Disscussion}

By Equation (3), the production-side implicit carbon emissions of China were computed as 5,408.44 million tons, including 5,248.8 Mt to satisfy domestic demand and 159.64 Mt to satisfy the demand of China's top trade partners along the Belt and the Road. The results show that domestic demand is the main driver of China's productionside carbon emissions.

The implicit carbon emissions to satisfy foreign demand can be further divided into those from intermediate export commodities and those from final export commodities. For the top five trade partners of China along the Belt and the Road, the implicit carbon emissions from intermediate export commodities stood at 7.89 Mt for South Korea, $0.023 \mathrm{Mt}$ for India, 0.21 Mt for Indonesia, 0.59 Mt for Russia and 0.21 Mt for Turkey. Hence, South Korea accounts for $90 \%$ of the total volume. Figure 1 shows the industrial classification of China's implicit carbon emissions from intermediate commodities exported to South Korea. Note that the "Sum" means the total implicit carbon emissions from intermediate commodities exported to the five trade partners.

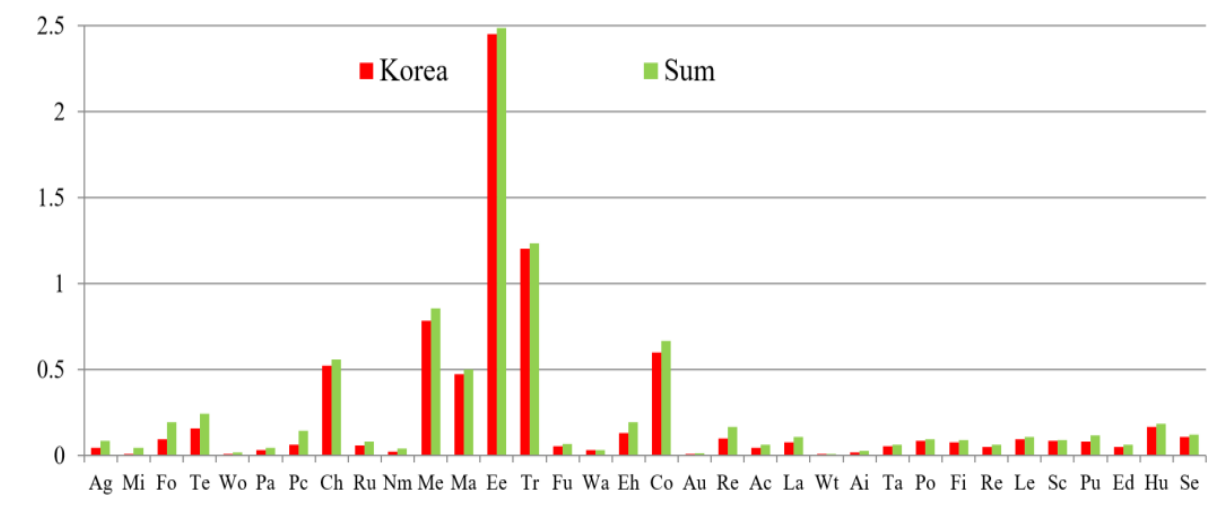

Figure 1. Industrial classification of China's implicit carbon emissions from intermediate commodities exported to South Korea

As shown in Figure 1, electric equipment production (Ee) generated $2.45 \mathrm{Mt}$ of implicit carbon emissions, about $98 \%$ of the total volume of the five trade partners. This industry is clearly the leading contributor to China's implicit carbon emissions from intermediate commodities exported to South Korea, followed by transport equipment production $(\mathrm{Tr})(1.20 \mathrm{Mt})$, metallurgy $(\mathrm{Me})(0.79 \mathrm{Mt})$, construction industry (Co) $(0.61 \mathrm{Mt})$, chemical industry $(\mathrm{Ch})(0.52 \mathrm{Mt})$ and machinery production $(\mathrm{Ma})(0.48 \mathrm{Mt})$. 
Figure 2 shows the industrial classification of China's implicit carbon emissions from intermediate commodities exported to the other four countries (India, Indonesia, Russia and Turkey). For Russia, the top 4 contributors to the said implicit carbon emissions include coke and refined oil production $(\mathrm{Pc})(0.06 \mathrm{Mt})$, retail goods $(\mathrm{Re})$ $(0.053 \mathrm{Mt})$, electricity and heating (Eh) $(0.052 \mathrm{Mt})$ and construction industry (Co) $(0.051 \mathrm{Mt})$. For Turkey, the top contributors include textile industry $(\mathrm{Te})(0.071 \mathrm{Mt})$, food industry (Fo) $(0.021 \mathrm{Mt})$ and construction industry $(\mathrm{Co})(0.010 \mathrm{Mt})$. For India, the top contributors include chemical industry (ch) $(0.003 \mathrm{Mt})$, textile industry (Te) $(0.024 \mathrm{Mt})$, automobile industry $(\mathrm{Au})(0.0024 \mathrm{Mt})$ and metallurgy $(\mathrm{Me})(0.0022 \mathrm{Mt})$. For Indonesia, the top contributors include food industry (Fo) $(0.03 \mathrm{Mt})$, coke and refined oil production $(\mathrm{Pc})(0.02 \mathrm{Mt})$, electric equipment production $(\mathrm{Ee})(0.017 \mathrm{Mt})$ and metallurgy $(\mathrm{Me})(0.015 \mathrm{Mt})$.

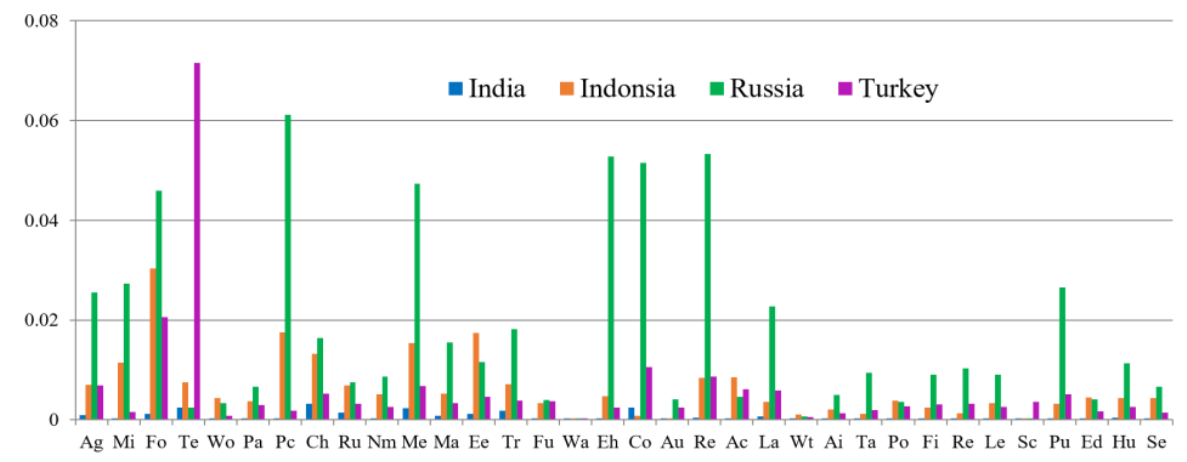

Figure 2. Industrial classification of China's implicit carbon emissions from intermediate commodities exported to India, Indonesia, Russia and Turkey

To sum up, the industries that produce high implicit carbon emissions from intermediate export commodities include electric equipment production (Ee), electricity and heating (Eh), metallurgy (Me) and machinery production (Ma), all of which are carbon intensive.

The five trade partners are ranked in descending order as South Korea, India, Indonesia, Russia and Turkey in terms of trade volume with China, and as South Korea, Russia, Indonesia, Turkey and Indiaby carbon emissions. On the implicit carbon emissions from China's intermediate export commodities, Russia comes at the top of the ranking with the volume of $50.98 \mathrm{Mt}$, followed by South Korea (33.61 Mt), India (27.06 Mt), Indonesia (20.92 Mt) and Turkey (18.15 Mt).

Figure 3 shows the industrial classification of China's implicit carbon emissions from final commodities exported to its top trade partners along the Belt and the Road. It can be seen that $79.95 \%$ of the carbon emissions of final exported products come from such industries as electricity and heating (Eh) (70.28 Mt), metallurgy (Me) (14.12 Mt), machinery production $(\mathrm{Ma})(15.69 \mathrm{Mt})$, water transport $(\mathrm{Wt})(9.42 \mathrm{Mt})$ and other transport (Ta) (10.99 Mt).

According to Equation (5), The consumption-side carbon emissions of China, which totals 5,503.89 Mt, are driven by either domestic demand (5,248.8 Mt) and foreign demand (2,282.09 Mt). Thus, most of China's consumption-side carbon emissions $(69.70 \%)$ originate from domestic demand-driven production. The foreign demanddriven emissions can be further split into those induced by direct import (2,022.28 Mt) and those resulted from indirect trade $(259.82 \mathrm{Mt})$. 
As shown in Figure 4, electric equipment production (Ee) (303.62 Mt) is the leading contributor to China's consumption-side carbon emissions induced by direct import, followed by metallurgy (Me) (220.61 Mt), construction industry (Co) (219.67 Mt), textile industry (Te) (133.51 Mt), chemical industry $(\mathrm{Ch})(143.88 \mathrm{Mt})$ and food industry (Fo) $(110.94 \mathrm{Mt})$. In total, these six industries take up $55.99 \%$ of all direct importinduced carbon emissions.

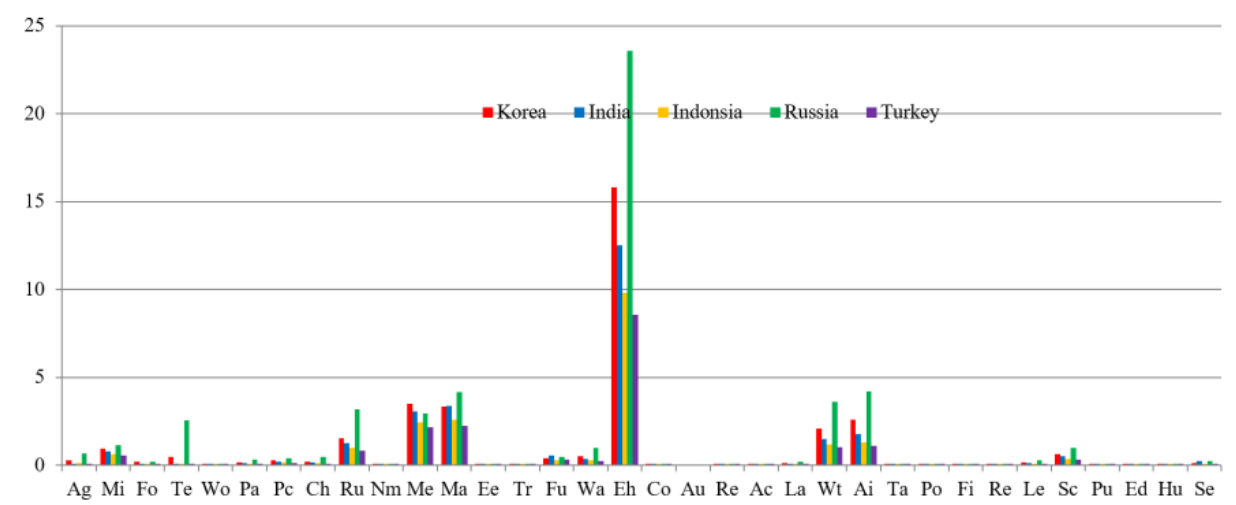

Figure 3. Industrial classification of China's implicit carbon emissions from final commodities exported to the five trade partners

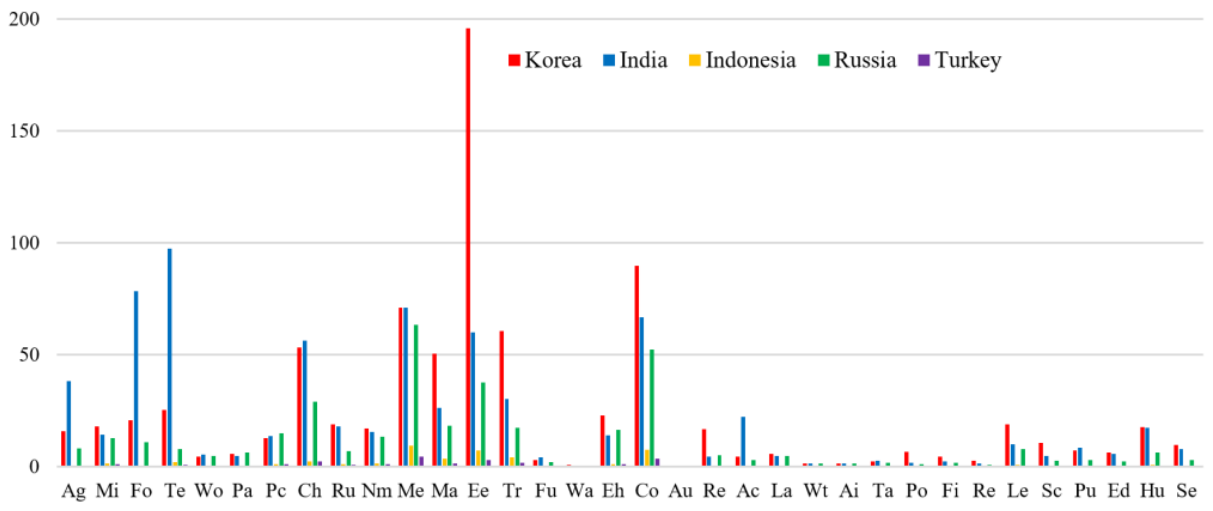

Figure 4. Industrial classification of China's consumption-side carbon emissions induced by direct import

The carbon emissions induced by indirect trade refers to those arising from the trade between China and the foreign countries. Coupled with the direct import of intermediate/ final commodities, the indirect trade of commodities determines the final demand of a country in the complex network of global division of labor. For the indirect trade-induced emissions, the leading contributor is electric equipment production (Ee) (52.74 Mt), accounting for $20.30 \%$ of the total indirect emissions, followed by metallurgy (Me) (34.34 Mt) (13.22\%), coke and refined oil production (Pc) (28.85 Mt) $(11.11 \%)$, electricity and heating (Eh) $(13.47 \mathrm{Mt})(5.52 \%)$.

Figure 5 illustrates the calculated responsibilities of China under different sharing principles. As shown in the figure, China needs to assume responsibility for 5,408.44 Mt of carbon emissions in its trade with the countries along the Belt and the Road under the producer responsibility system, 7,503.89 Mt under the consumer 
responsibility system, and 6,681.91 under the common responsibility system. The responsible amount under the consumer responsibility is 1.39 times that under the producer responsibility, and 1.13 times that under the common responsibility. This is because China imports more commodities from the countries along the Belt and the Road than its export volume to these countries. Comparatively, the common responsibility system is relatively fair, as China needs to assume part of the carbon emissions caused by imported commodities, which is relatively fair.

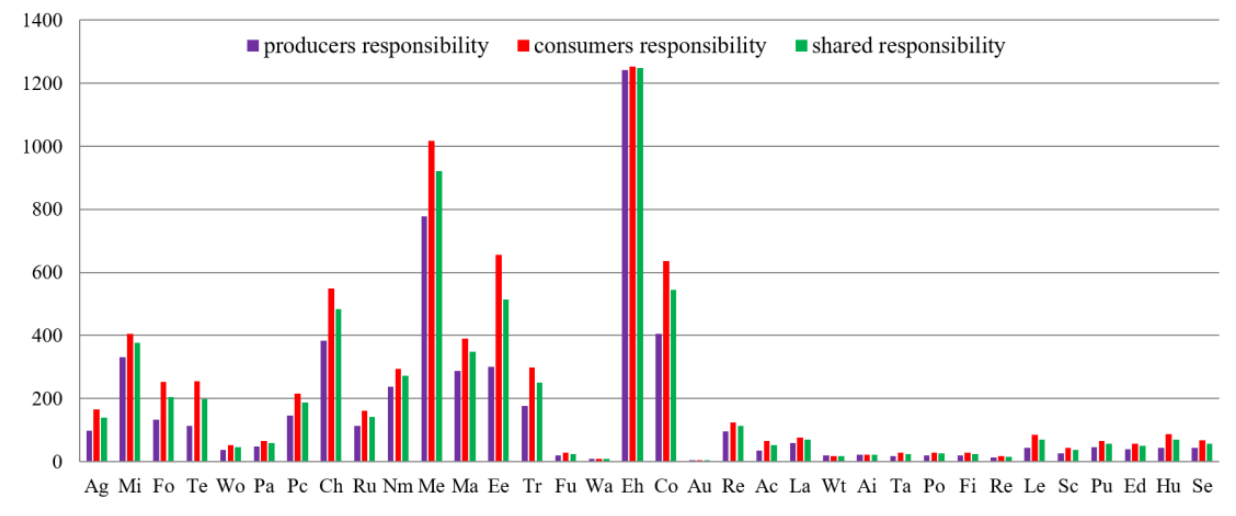

Figure 5. Responsibility of China under different sharing principles

The six industries that contribute the most to carbon emissions were selected to analyze their responsibilities under the three sharing principles.

For the leading contributor electricity and heating (Eh), its carbon emission responsibilities will be 1,240.77 Mt, 1,252.49 Mt and 1,247.81 Mt, respectively, under the producer responsibility, consumer responsibility and common responsibility. There is not much difference for this industry under the three sharing principles.

For the second largest emitter metallurgy $(\mathrm{Me})$, its carbon emission responsibilities will be $777.98 \mathrm{Mt}, 1,017.96 \mathrm{Mt}$ and $921.97 \mathrm{Mt}$, respectively, under the producer responsibility, consumer responsibility and common responsibility. The responsible volume under consumer responsibility is 1.31 times that of producer responsibility.

For other large emitters like chemical industry $(\mathrm{Ch})$, electric equipment production (Ee), mining industry (Mi) and machinery production (Ma), the gap between consumer responsibility and producer responsibility in responsible volume is even greater. For these industries, the responsible volume under consumer responsibility is 1.55 times, 2.17 times and 1.22 times that under producer responsibility, respectively.

The huge difference mainly arises from two factors: the industrial difference in carbon emission intensity and the shift in carbon emissions under international trade. For one thing, different industries differ widely in carbon emission intensity. Mining, energy and power industries emit carbon much more intensively than education and scientific research, exerting a high pressure for emission reduction in China. Of course, this also promises a high potential of the country for emission reduction. For another, integration is the main theme of global economic development. This trend brings huge benefits to China's economy. However, it also causes the transfer of carbon emissions, giving the country many unnecessary responsibilities for emission reduction. 


\section{Conclusion}

As the world's largest carbon emitter, China is facing more and more pressure on coping with global climate change. Based on the WIOD database, this paper measures the trade volume between China and its leading trade partners on the Belt and the Road using the MRIO model, revealing the implicit carbon emissions in the trade, and analyzes China's responsibilities for reducing implicit carbon emissions in trade from different perspectives. The main conclusions of this research are as follows:

(1) China's carbon responsibilities in its trade with the top trade partners differs greatly with responsibility sharing principles. The responsible volume under consumer responsibility is much greater than the traditional producer responsibility system. Thus, China and other developing countries should highlight the fairness of responsibility sharing in international negotiations on climate, trying to develop a carbon accounting mechanism favorable to their own rights and interests.

(2) Implicit carbon emissions mainly come from industries with relatively high emission intensities, such as electricity, energy, mining, and chemical industry. All these industries are featured by high energy-consumption and low efficiency. The coalbased energy structure is the fundamental reason for China's high carbon emissions. In future, efforts should be made to increase energy efficiency, increase the proportion of clean energy in the energy structure, and promote the transition towards a clean and efficient consumption structure.

(3) Comparing the different responsibility sharing principles, China is advised to adopt the common responsibility mechanism, which is relatively fair for regions with a large amount of implicit carbon influx.

The future research will clarify China's carbon responsibilities in international trade, assess its emission reduction potential, and allocate the carbon emission responsibilities.

Acknowledgements. Acknowledgements. This work was supported by the Think-tank Program of Education Department in Shaanxi (Nos. 18JT008, 18JT011)., Soft Science Program of Shaanxi Province (Nos. 2019KRM027, 2019KRM109), and National Natural Science Foundation of China (Nos. 71704140, 71804097).

\section{REFERENCES}

[1] Bello, M. O., Solarin, S. A., Yen, Y. Y. (2018): The impact of electricity consumption on $\mathrm{CO} 2$, emission, carbon footprint, water footprint and ecological footprint: the role of hydropower in an emerging economy. - Journal of Environmental Management 219: 218.

[2] Boamah, K. B., Du, J. G., Bediako, I. A., Boamah, A. J., Abdul-Rasheed, A. A., Owusu, S. M. (2017): Carbon dioxide emission and economic growth of china-the role of international trade. - Environmental Science and Pollution Research 24(14): 1304913067.

[3] Cozier, M. (2016): The un cop21 climate change conference and the role of ccs. Greenhouse Gases Science \& Technology 5(6): 697-700.

[4] Dietzenbacher, E., Pei, J., Yang, C. (2012): Trade, production fragmentation, and China's carbon dioxide emissions. - Journal of Environmental Economics \& Management 64(1): $88-101$.

[5] Dong, F., Long, R., Yu, B. (2018): How can China allocate CO2, reduction targets at the provincial level considering both equity and efficiency? Evidence from its Copenhagen Accord pledge. - Resources Conservation \& Recycling 130: 31-43. 
[6] Fang, F., Xu, H. Y. (2013): Carbon Dioxide Emissions Embodied in China's International Trade:Estimation and Analysis Based on Multi-Regional Input-Output Model. - Journal of International Trade (9): 82-91.

[7] Gao, J., Liu, G. G. (2016): Embodied Carbon Emissions Accounting, Structure Decomposition and Allocation of responsibilites in Global Trade: Based on Single-region and Multi-region I-O Methods' Comparison. - Shanghai Journal of Economics 1: 34-43, 70.

[8] Lan, Z. X. (2015): The Estimation of the Implied Carbon Emission of China-EU Bilateral Trade and the Influencing Factors. - Guangdong University of Finance and Economics.

[9] Li, B. (2016): Research on carbon flow and product carbon footprint in export trade. Beijing Institute of Technology.

[10] Li, Q. R. (2017): China and Japan's calculation of the implied carbon trade in countries along the 'One Belt and One Road'and analysis of influencing factors. - Modern Japan Economics 4: 69-84.

[11] Li, Q., Wen, B., Wang, G. (2018): Study on calculation of carbon emission factors and embodied carbon emissions of iron-containing commodities in international trade of china. - Journal of Cleaner Production 191: 119-126.

[12] Liu, Y., Meng, B., Hubacek, K. (2016): 'Made in China': A reevaluation of embodied $\mathrm{CO} 2$, emissions in Chinese exports using firm heterogeneity information. - Applied Energy 184: 1106-1113.

[13] Liu, Y., Tian, Y., Chen, M. (2017): Research on the prediction of carbon emission based on the chaos theory and neural network. - International Journal Bioautomation 21(S4): 339-348.

[14] Munksgaard, J. (2001): CO2 accounts for open economies: producer or consumer responsibility? - Energy Policy 29(4): 327-334.

[15] Pan, J., Phillips, J., Chen, Y. (2008): China's balance of emissions embodied in trade: approaches to measurement and allocating international responsibility. - Oxford Review of Economic Policy 24(2): 354-376.

[16] Pan, A., Wu, X. L. (2018): A Study on Embodied Carbon Emissions in Sino-Japan Trade from the Perspective of GVC Division. - Contemporary Economy of Japan 37(2): 40-52.

[17] Shi, S., Li, C. X., Li, M. T. (2017): Research Progress in the Accounting Method of "Carbon Emission" to "Carbon Footprint" in Animal Husbandry. - Chinese Journal of Population, Resources and Environment 27(6): 36-41.

[18] Su, B., Ang, B. W. (2011): Input-output analysis of CO emissions embodied in trade: The effects of spatial aggregation. - Energy Economics 32(1): 166-175.

[19] Sun, Y. Y. (2016): Research on the Influencing Factors of the Implied Carbon Emission of China's Export Trade. - Dongbei University of Finance and Economics.

[20] Tan, S. L., Qiu, G. Y., Xiong, Y. (2014): New Application of Input-Output Method in Virtual Water Consumption and Trade Research. - Journal of Natural Resources 29(2): 355-364.

[21] Tu, J. Z., Ma, D. L. (2018): A spatial economics perspective on convergence research of carbon emissions performance in China. - International Journal of Heat and Technology 36(3): 962-972.

[22] Wang, A. J., Feng, Z. X., Meng, B. (2017): Measure of Carbon Emission and Carbon Transfer in 30 Provinces of China. - Journal of Quantitative \& Technical Economics 34(8): 89-104.

[23] Wei, T., Peng, S. J. (2017): Research on Embodied Energy in China-USA Trade with MRIO Model. - Soft Science 31(8): 39-42, 70.

[24] Xia, Y., Fan, Y., Yang, C. (2015): Assessing the impact of foreign content in China's exports on the carbon outsourcing hypothesis. - Applied Energy 150: 296-307.

[25] Xiao, Y., Zheng, X. D. (2016): Research on the Trade Value-Adding and Carbon Emission Commitment Under Global Value Chain. - Theoretical Exploration 4: 172-176. 
[26] Yu, T., Wang, W. Z. (2017): Measurement and Decomposition of Implicit Carbon Emissions in China's Foreign Trade. - Ecological Economy 33(7): 37-41.

[27] Yu, X. H., Xu, M. (2017): Research on the Responsibility of China's Industrial Sector for External Trade Carbon Emission from the Perspective of Consumer Responsibility. Industrial Economic Review 8(1): 18-30.

[28] Zhang, S. E. (2017): Study on dynamic performance modeling for carbon emission of machinofacture system based on mixed space model. - Academic Journal of Manufacturing Engineering 15(2): 87-94.

[29] Zhong, Z. Q., Zhang, X., He, L. Y. (2018): Regional Carbon Emissions Transfer, Embodied Emissions in Trade Per Unit of Value of Trade and Regional Cooperation: Empirical Analysis from 30 Provinces in China. - Journal of International Trade 73(3): 94-104. 